\title{
Smear positive pulmonary tuberculosis and its risk factors among tuberculosis suspect in South East Ethiopia; a hospital based cross-sectional study
}

Begna Tulu ${ }^{1,2^{*}}$, Nagasa Dida ${ }^{3}$, Yibeltal Kassa ${ }^{4}$ and Biruhalem Taye ${ }^{5}$

\begin{abstract}
Background: Tuberculosis remains a deadly infectious disease, affecting millions of people worldwide. Ethiopia ranks seventh among the twenty two high tuberculosis burden countries. The aim of this study was to determine the prevalence of smear positive pulmonary tuberculosis and its associated risk factors in Goba and Robe hospitals of Bale zone.

Methods: A cross-sectional study was conducted on tuberculosis suspected patients from February-May 2012. Sputum samples were examined for acid fast bacilli using Ziehl-Neelsen staining and interview was conducted for each patient. Descriptive statistics, binary logistic and multivariable logistic regression analyses were employed to identify factors associated with pulmonary tuberculosis infection.

Result: The prevalence of smear positive tuberculosis was 9.2\%. Age $>36(A O R=3.54,95 \% C l=1.3-9.82$ ), marital status ( $A O R=8.40,95 \% \mathrm{Cl}=3.02-23.20)$, family size $(A O R=4.10,95 \% \mathrm{Cl}=1.60-10.80)$, contact with active tuberculosis patient $(A O R=5.90 ; 95 \% \mathrm{Cl}=2.30-15.30)$, smoking cigarette regularly $(A O R=3.90 ; 95 \% \mathrm{Cl}=1$. 20-12.40), and human immunodeficiency virus sero-status ( $A O R=11.70 ; 95 \% \mathrm{Cl}=4.30-31.70$ ) were significantly associated with smear positive pulmonary tuberculosis.

Conclusion: The prevalence of smear positive pulmonary tuberculosis was high in the study area. Age, marital status, family size, history of contact with active tuberculosis patient, smoking cigarettes, and HIV sero-status were among the risk factors significantly associated with acquiring tuberculosis. Hence, strict pulmonary tuberculosis screening of HIV patients and intensification of health education to avoid risk factors identified are recommended.
\end{abstract}

Keywords: Smear positive PTB, Prevalence, Risk factors

\section{Background}

Tuberculosis (TB) is still one of the infectious diseases known by its significant cause of morbidity and mortality affecting millions of people worldwide. Although it is a global epidemic, TB predominantly affects developing countries, where $98 \%$ of worldwide TB death occurs

\footnotetext{
*Correspondence: begnaeticha@yahoo.com

${ }^{1}$ Microbiology, Immunology and Parasitology Department, College of Medicine and Health Sciences, Bahir Dar University, P. O. Box 79, Bahir Dar, Ethiopia

${ }^{2}$ Microbiology, Infectious Diseases and Parasitology Department, College of Medicine and Health Sciences, Madawalabu University, P. O. Box 302, Bale-Goba, Ethiopia

Full list of author information is available at the end of the article
}

$[1,2]$. Resource poor countries share the global burden with highest rates, with an estimated $55 \%$ of global case in Asia and 31\% in Africa [2-5]. According to the WHO Global TB Report, Ethiopia ranks seventh among the world's 22 high-burden TB countries. The estimated incidence rate was 261 cases per 100,000 population and 29 thousand deaths in 2010, with an estimated prevalence rate of 394 cases per 100,000 populations [2].

Studies have shown that human immunodeficiency virus (HIV)/AIDS, diabetes, cancer, malnutrition, alcoholism, smoking cigarette, active TB contact, extreme poverty, homelessness, and being in prison were among the commonly identified risk factors associated with 
tuberculosis in most developing countries including Ethiopia [6-9].

In Ethiopia, a study conducted in Metehara sugar factory hospital showed $14.2 \%$ prevalence of smear positive pulmonary tuberculosis [10]. Another study on smear positive TB conducted in Agaro health centre showed a prevalence of $10.9 \%$ [11]. However, the rate of pulmonary TB (PTB) and its associated risk factors in the study area were not known. Therefore, the purpose of this study was to determine the prevalence of smear positive PTB and its associated risk factors among PTB suspected patients attending Bale Goba and Robe Hospitals.

\section{Methods}

A cross-sectional study was conducted in Bale Goba and Robe Hospitals of Bale zone, which are $444 \mathrm{~km}$ and $432 \mathrm{~km}$ away from the capital city, Addis Ababa, respectively towards the South East part of Ethiopia. The study was conducted from February 01 to May 25, 2012. Sample size was calculated using single population proportion formula $\left[\mathrm{n}=(\mathrm{Z} \alpha / 2)^{2} \mathrm{P}(1-\mathrm{P}) / \mathrm{d}^{2}\right]$, where, $\mathrm{n}=$ sample size, $Z \alpha /{ }_{2}=$ statistic for the level of confidence at $95 \%$, which is $1.96, \mathrm{P}=$ expected prevalence which was set $50 \%$ to yield maximum sample size, and $d=$ precision which is $5 \%$. Including $10 \%$ non response rate the sample size became 420 . However, 391 of them participated with none response rate of 93.1."

Pretested questionnaire was used to collect information on socio-demographic characteristics and other associated risk factors. Data collectors were also trained for one day on the instrument of data collection and how to collect the sputum specimen and also supervised by the investigators during the entire data collection.

Three consecutive sputum samples, i.e. spot-morningspot were collected from each of the PTB suspected cases. Experienced laboratory technologists performed the laboratory test following the standard procedure of Ziehl-Neelsen staining technique recommended by WHO $[12,13]$. The completeness of the questionnaire was checked and the examination sputum samples were performed both in the hospital's laboratory and Madawalabu University Biomedical Laboratory for quality control. Provider initiative counseling and testing (PIHCT) for HIV is being practiced for all TB suspects hence, HIV results were collected from hospital records with patient card numbers.

The data from questionnaires and laboratory results were analyzed using statistical software (SPSS package version 16). The results were summarized using descriptive statistics including frequencies and mean. Difference of proportion was evaluated using Chi-square test and $\mathrm{p}<0.05$ was considered as significant. A binary and multiple logistic regression analysis were used and odds ratio was calculated to determine the strength of association between variables and lifetime exposure to TB infection.
The study was approved by Research Ethics and Review Committee of Madawalabu University. In addition, official permission was obtained from the administration offices of Goba and Robe Hospitals. Furthermore, the objective of the study was explained to the participants and written consent was obtained before specimen collection. All participants who were affected by the disease were treated in the hospital accordingly.

\section{Result}

Socio-demographic characteristics of tuberculosis suspected patients

Out of the total study participants, $55.1 \%$ were residence of urban setup, and $52.9 \%$ were males. The mean age of the study participants was 40.8 years (std. deviation \pm 20 . 2). Concerning their marital status, $71.9 \%$ were married. Illiterate study participants constitute $50.1 \%$, followed by primary education (1-8) which was $33.8 \%$.

Regarding their living situation, $98.2 \%$ of the study participants live together with their family or relatives while the rest $1.8 \%$ of them live in prison and on the street. A majority, $57.5 \%$ of the study participants reported that they had family member of five or less while the rest $42.5 \%$ of them posses a family member of more than five. With regard to the number of rooms in the respondents' home, $89.0 \%$ of them reported they have three or less rooms while the rest reported they have more than three. The predominant occupational status of the study participants was unemployed $43.4 \%$, followed by farmer 38.1\% (Table 1).

\section{Prevalence of smear positive pulmonary tuberculosis}

The prevalence of smear positive PTB supported by chest $\mathrm{x}$-ray in the study population was $9.2 \%$. The result also showed $39.0 \%$ of the study participants were co-infected with smear positive PTB and HIV. Urban residents were more frequently infected with smear positive PTB than compared to rural ones $(p=0.029)$. A significantly higher proportion of smear positive TB was reported among older ages, $\geq 36$ years $(p=0$. 005). Smear positive PTB was also more frequently reported among those having $>5$ family member $(p=0.017)$. Similarly, unmarried individuals were found to be more frequently infected with smear positive PTB compared to married ones $(\mathrm{p}=0$. 022) (Table 1).

\section{Risk factors associated with smear positive pulmonary tuberculosis}

Based on bivariate logistic regression, HIV sero-status, smoking cigarette regularly, and history of contact with the active TB patient were significantly associated with smear positive $\mathrm{PTB}(\mathrm{OR}=10.50,95 \% \mathrm{CI}=4.80-22.80$, $\mathrm{OR}=4.20,95 \% \mathrm{CI}=1.80-9.80$, and $\mathrm{OR}=2.40,95 \% \mathrm{CI}=$ 1. 20-5.10 respectively). However, previous TB infection, 
Table 1 Socio-demographic characteristics and the proportion of smear positive tuberculosis in different categories of the study subjects in Goba and Robe Hospitals, 2012

\begin{tabular}{|c|c|c|c|}
\hline Characteristics & & $\mathrm{N}(\%)$ SPTB $^{*}$ & P value ${ }^{* *}$ \\
\hline \multirow[t]{2}{*}{ Residence } & Urban & $26(72.2)$ & 0.029 \\
\hline & Rural & $10(27.8)$ & \\
\hline \multirow[t]{2}{*}{ Sex } & Male & 20(55.6) & 0.742 \\
\hline & Female & $16(44.4)$ & \\
\hline \multirow[t]{3}{*}{ Age (years) } & $\leq 15$ & 0 & 0.005 \\
\hline & $16-35$ & $8(22.2)$ & \\
\hline & $\geq 36$ & 28(77.8) & \\
\hline \multirow[t]{2}{*}{ Marital status } & Unmarried ${ }^{* * *}$ & $16(44.4)$ & 0.022 \\
\hline & Married & $20(55.6)$ & \\
\hline \multirow{3}{*}{$\begin{array}{l}\text { Educational } \\
\text { status }\end{array}$} & Illiterate & $16(44.4)$ & 0.331 \\
\hline & Grade 1-8 & $16(44.4)$ & \\
\hline & Grade 9 and above & $4(11.1)$ & \\
\hline \multirow[t]{2}{*}{ Living Situation } & $\begin{array}{l}\text { Living in prison \& on } \\
\text { the street }\end{array}$ & $3(8.3)$ & 0.002 \\
\hline & Living with family & 33(91.7) & \\
\hline \multirow[t]{2}{*}{ Family size } & $>5$ & 22(61.1) & 0.017 \\
\hline & $\leq 5$ & 14(38.9) & \\
\hline \multirow[t]{2}{*}{ Number of rooms } & $\leq 3$ & $34(94.4)$ & 0.273 \\
\hline & $>4$ & $2(5.6)$ & \\
\hline \multirow[t]{3}{*}{ Occupation } & Employee & $6(16.7)$ & 0.290 \\
\hline & Unemployed & 12(33.3) & \\
\hline & Farmer & $18(50.0)$ & \\
\hline
\end{tabular}

${ }^{*}$ Smear positive PTB, ${ }^{* *} x^{2}$ test for trends ${ }^{* * *}$ Single, widowed and divorced.

regular alcohol use, repeated respiratory tract infections, family history of $\mathrm{TB}$, and diabetic cases were found to be statistically insignificant $(\mathrm{p}>0.05)$ with smear positive PTB (Table 2).

After adjusting for those significantly associated variables, age $(\mathrm{p}=0.015)$, marital status $(\mathrm{p}<0.001)$, family size $>5(\mathrm{p}=0.004)$, history of active TB patient contact $(p<0.001)$, history of smoking cigarette $(p=0.021)$ and HIV sero-status $(\mathrm{p}<0.001)$ remains significant associated with smear positive PTB. However, factors like place of residence, and living situations were not significantly associated with smear positive PTB with $(\mathrm{p}>0.05)$ (Table 3).

Respondents who were above the age of 36 were about four times ( $\mathrm{AOR}=3.54,95 \% \mathrm{CI}=1$. 3-9.82) more likely to develop smear positive PTB compared to those younger ages. Similarly, unmarried respondents were about eight times $(\mathrm{AOR}=8.40,95 \% \mathrm{CI}=3.02-23.20)$ more likely to develop smear positive PTB than married ones. Those who had contact with active TB patient in their vicinity were about six times $(\mathrm{AOR}=5.90 ; 95 \% \mathrm{CI}=2$. 30-15.30) more likely to develop smear positive TB than
Table 2 Exposure status to different TB risk factors and proportions of TB positive participants at Goba and Robe Hospitals, 2012

\begin{tabular}{|c|c|c|c|}
\hline Characteristics & N (\%) SPTB & $\begin{array}{c}\text { Crude OR } \\
(95 \% \mathrm{Cl})\end{array}$ & P-value \\
\hline \multicolumn{4}{|l|}{ Previous TB infection } \\
\hline Yes & $8(22.2)$ & $1.30[0.56-2.90]$ & 0.544 \\
\hline No & 28(77.8) & 1 & \\
\hline \multicolumn{4}{|l|}{ Family History of TB } \\
\hline Yes & $10(27.8)$ & $2.10[0.96-4.60]$ & 0.064 \\
\hline No & $26(72.2)$ & 1 & \\
\hline \multicolumn{4}{|c|}{ Contact with active TB patient } \\
\hline Yes & 12(33.3) & $2.40[1.20-5.10]$ & 0.021 \\
\hline No & $24(66.7)$ & 1 & \\
\hline \multicolumn{4}{|c|}{ Smoking cigarette regularly } \\
\hline Yes & $9(25.0)$ & $4.20[1.8-9.80]$ & 0.001 \\
\hline No & $27(75.0)$ & 1 & \\
\hline \multicolumn{4}{|c|}{ Drinking alcohol regularly } \\
\hline Yes & $5(13.9)$ & $1.00[0.38-2.74]$ & 0.974 \\
\hline No & $31(86.1)$ & 1 & \\
\hline \multicolumn{4}{|l|}{ HIV sero-status } \\
\hline Positive & $16(44.4)$ & $10.50[4.80-22.80]$ & $<0.001$ \\
\hline Negative & 20(55.6) & 1 & \\
\hline
\end{tabular}

those who were not. Those who reported smoking cigarette regularly were also about four times $(\mathrm{AOR}=3$. 90; $95 \% \mathrm{CI}=1.20-12.40$ ) more likely to develop smear positive TB than those who do not smoke. Concerning HIV sero-status, those who were HIV positive were about twelve times $(\mathrm{AOR}=11.70 ; 95 \% \mathrm{CI}=4.30-31.70)$ more likely to develop than who were HIV negative (Table 3).

\section{Discussion}

This study tries to provide insights into the prevalence of smear positive PTB among tuberculosis suspected patients attending Bale Robe and Goba hospitals, as well as outline some possible risk factors. The results showed 9.2\% prevalence of smear positive PTB. This shows that $\mathrm{TB}$ is still one of the major public health concerns in the study area and in Ethiopia as well. Similar studies conducted in Rwanda reported (17.3\%) [5], and in Nigeria (14.7\%) [14] which was significantly higher compared to the findings in this study. This may be due to the community based program launched several years ago using home to home community health workers, who are capable of creating awareness better than the previous strategies in Ethiopia. The result in this study was in line with similar study conducted in hospitals and health centers of Ethiopia; Agaro Teaching Health Center, (10.9\%) [11], Jimma University Specialized Hospital, (8.5\%) [15], 
Table 3 Adjusted Odds Ratio of exposure status to different TB risk factors and proportions of TB positive participants at Goba and Robe Hospitals, 2012

\begin{tabular}{|c|c|c|c|c|c|}
\hline Characteristics & N (\%) SPTB & Crude OR $(95 \% \mathrm{Cl})$ & P-value & Adjusted OR $(95 \% \mathrm{Cl})$ & P-value \\
\hline \multicolumn{6}{|l|}{ Residence } \\
\hline Urban & $26(72.2)$ & $2.28[1.07-4.87]$ & 0.033 & - & - \\
\hline Rural & $10(27.8)$ & 1 & & - & \\
\hline \multicolumn{6}{|l|}{ Age (yrs) } \\
\hline $16-35$ & $8(22.2)$ & 1 & & 1 & \\
\hline$>36$ & $28(77.8)$ & $2.97[1.32-6.71]$ & 0.032 & $3.54[1.3-9.82]$ & 0.015 \\
\hline \multicolumn{6}{|l|}{ Marital status } \\
\hline Unmarried & $16(44.4)$ & $2.22[1.11-4.47]$ & 0.025 & $8.40[3.02-23.20]$ & $<0.001$ \\
\hline Married & 20(55.6) & 1 & & 1 & \\
\hline \multicolumn{6}{|l|}{ Living Situation } \\
\hline In prison \& on street & $3(8.3)$ & $7.98[1.71-37.20]$ & 0.008 & - & - \\
\hline With family & $33(91.7)$ & 1 & & - & \\
\hline \multicolumn{6}{|l|}{ Family size } \\
\hline$>5$ & 14(38.9) & $2.30[1.10-4.70]$ & 0.020 & $4.10[1.60-10.80]$ & 0.004 \\
\hline$\leq 5$ & $22(61.1)$ & 1 & & 1 & \\
\hline \multicolumn{6}{|l|}{ Active TB patient contact } \\
\hline Yes & $12(33.3)$ & $2.40[1.20-5.10]$ & 0.021 & $5.90[2.30-15.30]$ & $<0.001$ \\
\hline No & $24(66.7)$ & 1 & & 1 & \\
\hline \multicolumn{6}{|l|}{ Smoking cigarette } \\
\hline Yes & $9(25.0)$ & $4.20[1.8-9.80]$ & 0.001 & $3.90[1.20-12.40]$ & 0.021 \\
\hline No & $27(75.0)$ & 1 & & 1 & \\
\hline \multicolumn{6}{|l|}{ HIV sero-status } \\
\hline Positive & $16(44.4)$ & $10.50[4.80-22.80]$ & $<0.001$ & $11.70[4.30-31.70]$ & $<0.001$ \\
\hline Negative & $20(55.6)$ & 1 & & 1 & \\
\hline
\end{tabular}

and in Jimma Seka (10.6\%) [16]. However, the finding of the present study showed lower prevalence than similar study conducted in Tigray (17.7\%) [17], in Addis Ababa (21.3\%) [18], and in Eastern Ethiopia 14.2\% [10]. This could be associated to differences in awareness level of the patients leading to passive detection in those who had sign and symptoms of the disease.

This study also indicated that the prevalence of smear positive PTB was significantly higher in HIV positive patients than HIV-negative. Out of the total 36 smear positive pulmonary tuberculosis $44.4 \%$ were HIV positive. Similarly, a number of studies conducted in different parts of the world and some other African countries showed the prevalence rate of co-infection ranges from $8 \%$ in Congo to $82 \%$ in Swaziland [3,5,19]. In Ethiopia, based on the WHO report in 2012 the rate of coinfection was (41\%) [2]. As it is well established the strong association between HIV and TB is attributed to the overlapping of the age group that both infections are affecting and the immunological deprivation that HIV results in.
As far as sex is concerned, similar studies conducted in Ethiopia and other countries like Rwanda, and Myanmar, reported that smear positive PTB is more common among men than women $[2,5,15,20-22]$. In the present study, the prevalence of smear positive tuberculosis was not statistically significant between sexes, though a relatively higher prevalence was reported among men $55.6 \%$, and women 44.4\%. Similar to previous studies conducted in Ethiopia and other countries $[5,15,20,21]$, smear positive PTB affects mostly adults in the economically productive age groups; around two-thirds of cases were estimated to occur among people aged $15-59$ years.

Urban dwellers were found to be more associated with smear positive TB in this study. The prevalence of smear positive PTB was $72.2 \%$ among urban dwellers compared to $27.8 \%$ among the rural dwellers. This finding is consistent with similar studies conducted in India (69.2\%) and Ethiopia (52.7\%) [9,23]. This might be due to the fact that urban set up is characterized by overcrowding and suffocation which is an important risk for respiratory disease including tuberculosis. 
The role of active smoking in the development of TB is well known $[2,6]$, the same is true in this study in which active smoking was significantly associated with smear positive TB with $(\mathrm{p}=0.021)$. A history of active TB patient contact and HIV- sero status was also among the risk factors that showed significant association with smear positive TB $(\mathrm{P}<0.005)$. This is consistent with WHO report and studies conducted in different parts of the world $[2,6,24]$.

Some of the limitations of this study include direct smear microscope alone may underestimate the prevalence of PTB in the study population. Other techniques like culture and molecular assays could best estimate the prevalence of PTB among the study subjects. However, due to financial constraints, we were unable to perform these advanced tests. Selection bias may also arise from convenience sampling.

\section{Conclusion}

In conclusion, the prevalence of smear positive PTB among tuberculosis suspect was high (9.2\%) in Bale Goba and Robe hospitals. Smear positive PTB was more frequently reported among urban residence, age $>36$ years, male sex, and unemployed individuals. Risk factors like HIV sero-status, active TB patient contact, and cigarette smoking were significant to acquire smear positive TB. Hence, we recommend strict PTB screening of HIV patients, and health education to avoid smoking. It would be better to expand health education to household contacts of smear positive PTB patients on how to protect them from TB infection. Finally, we would also like to recommend longitudinal studies with more advanced laboratory techniques.

\section{Competing interest}

None of the authors and other organizations has competing interest.

\begin{abstract}
Author's contribution
$\mathrm{BT}^{*}$ and ND conceptualized and designed the study. BT and YK assisted in designing the study design. $B T^{*}, N D$ and $Y K$ analyzed and interpreted the data, drafted the manuscript and critically reviewed the manuscript. BT assisted in drafting and critically reviewing the manuscript. All the authors' read and approved the manuscript.
\end{abstract}

\section{Acknowledgements}

We would like to acknowledge the Research and Community Services Directorate of Madawalabu University for funding this study. We are also grateful for the College of Medicine and Health Sciences of Madawalabu University in assisting this study by allowing the laboratory facility. Medical laboratory technologists and TB clinic staff of Goba and Robe hospitals, and the study subjects also deserve our special appreciation. Finally, we would like to appreciate the role of Mrs Eden Amsalu in editing the language of the manuscript.

\section{Author details}

'Microbiology, Immunology and Parasitology Department, College of Medicine and Health Sciences, Bahir Dar University, P. O. Box 79, Bahir Dar, Ethiopia. ${ }^{2}$ Microbiology, Infectious Diseases and Parasitology Department, College of Medicine and Health Sciences, Madawalabu University, P. O. Box 302, Bale-Goba, Ethiopia. ${ }^{3}$ Department of Public Health, College of Medicine and Health Sciences, Madawalabu University, P. O. Box 302, Bale-Goba,
Ethiopia. ${ }^{4}$ Department of Nursing, College of Medicine and Health Sciences, Madawalabu University, P. O. Box 302, Bale-Goba, Ethiopia. ${ }^{5}$ Tropical and Infectious Diseases Department, Aklilu Lemma Institute of Pathobiology, Addis Ababa University, P. O. Box 1176, Addis Ababa, Ethiopia.

Received: 25 November 2013 Accepted: 29 April 2014

Published: 6 May 2014

\section{References}

1. Grange J, Zumla A: The global emergency of tuberculosis: what is the cause? J R Soc Promot Health 2002, 122:78-81.

2. WHO: Global Tuberculosis Report. Geneva: World Health Organization; 2012.

3. WHO: Seventh meeting of the Strategic and Technical Advisory Group for Tuberculosis (STAG-TB): report on conclusions and recommendations. Geneva: World Health Organization; 2007.

4. WHO: World Health Report 2007- Global tuberculosis control- surveillance, planning, financing. Geneva: World Health Organization; 2007.

5. Muvunyi CM, Masaisa F, Bayingana C, Musemakweri A, Mutesa L, Hernandez TC: Prevalence and diagnostic aspects of sputum smear positive tuberculosis cases at a tertiary care institution in Rwanda. Afr J Micro Research 2010, 4:088-091.

6. Hussain H, Akhar S, Nanan D: Prevalence of and risk factors associated with Mycobacterium tuberculosisinfection in prisoners, North West Frontier Province. Pakistan Int J Epid 2003, 32:794-799.

7. Zaman K, Yunus M, Arifeen SE, Baqui AH, Sack DA, Hossain S, Rahim Z, Ali M, Banu S, Islam MA, Begum N, Begum V, Breiman RF, Black RE: Prevalence of sputum smear-positive tuberculosis in a rural area in Bangladesh. Epidemiol Infect 2006, 134:1052-1059.

8. Baker MA, Anthony D, Harries AD, Jeon CY, Hart JC, Kapur A, Lönnroth K, Ottmani SE, Goonesekera SD, Murray MB: The impact of diabetes on tuberculosis treatment outcomes: a systematic review. BMC Med 2011, 9:81.

9. Amare H, Gelaw A, Anagaw B, Gelaw B: Smear positive pulmonary tuberculosis among diabetic patients at the Dessie referral hospital, Northeast Ethiopia. Infectious Diseases of poverty 2013, 2:6.

10. Yohanes A, Abera S, Ali S: Smear positive pulmonary tuberculosis among suspected patients attending Metehara sugar factory hospital; eastern Ethiopia. Afr Health Sci 2012, 12(3):325. 30.

11. Ali H, Zeyudin A, Mekonnen A, Abera S, Ali S: Smear Positive Pulmonary Tuberculosis (PTB) Prevalence amongst Patients at Agaro Teaching Health Center, South West Ethiopia. Ethiop J Health Sci 2012, 22:71-76.

12. WHO: Global Tuberculosis Programme. Laboratory services in tuberculosis control. Geneva: World Health Organization; 1998.

13. Enarson DA, Rieder HL, Aranadottir T, Trebucq A: In: Management of tuberculosis: a guide for low-income countries, Paris. Int Union Against Tuber Lung Dis 2000, 1:89.

14. Imam T, Oyeyi T: Retrospective study of PTB prevalence among patients attending in infectious disease hospital. Bayero J pure applaid sci 2008, 1:10-15.

15. Gerbeselassie S: Evaluation of the concentration sputum smear technique for the lab diagnosis of PTB. Ethiop Med J 2003, 33:160-162.

16. Gebre D, Miamo L: Prevalence of smear positive pulmonary tuberculosis among patients attending Seka Health Center, Jimma, Oromia Region. Ethiopia East Afr J Public Health 2010, 7(3):268-273.

17. Mesfin MM, Tasew TW, Richard MJ: The quality of tuberculosis diagnosis in districts of Tigray region of northern Ethiopia. Ethiop J Health Dev 2005, 19:13-20.

18. Deribew A, Negussu N, Melaku Z, Deribe K: Investigation Outcomes of Tuberculosis Suspects in the Health Centers of Addis Ababa, Ethiopia. PLOS ONE 2011, 6(4):e18614.

19. Houston S, Ray S, Mahari M, Neill P, Legg W, Latif A, Emmanuel J, Bsset M, Pozaniak A, Tswana S: The association of tuberculosis and HIV infection in Harare. Zimbabwe Tuber Lung Dis 1994, 75:220-226.

20. Shargie $E$, Yassin $M$, Lint B: Smear positive pulmonary TB in rural district of Ethiopia. Int I tuber Lung Dis 2006, 10:87-97.

21. Minstry of Health (MOH): Report on National TB Prevalence Survey 2009-2010. Myanmar: MOH; 2010.

22. Deribew A, Aabebe $G$, Apers $L$, Abdissa A, Deribew F, Woldemichael $K$, Jira C, Tesfaye M, Shiffa J, Aseffa A, Bezabih M, Abeje T, Colebundrs R: Prevalence of pulmonary TB and spoligotype pattern of Mycobacterium tuberculosis among TB suspects in a rural community in Southwest Ethiopia. BMC Infect Dis 2012, 12. 
23. Stevenson CR, Forouhi NG, Roglic G, Williams BG, Lauer JA, Dye C, Unwin N: Diabetes and tuberculosis: the impact of the diabetes epidemic on tuberculosis incidence. BMC Publ Health 2007, 7:234.

24. Davies PD, Yew WW, Ganguly D, Davidow AL, Reichman LB, Dheda K, Rook GA: Smoking and tuberculosis: the epidemiological association and pathogenesis. Trans R Soc Trop Med Hyg 2006, 100(4):291-298.

doi:10.1186/1756-0500-7-285

Cite this article as: Tulu et al: Smear positive pulmonary tuberculosis

and its risk factors among tuberculosis suspect in South East Ethiopia; a

hospital based cross-sectional study. BMC Research Notes 2014 7:285.

\section{Submit your next manuscript to BioMed Central and take full advantage of:}

- Convenient online submission

- Thorough peer review

- No space constraints or color figure charges

- Immediate publication on acceptance

- Inclusion in PubMed, CAS, Scopus and Google Scholar

- Research which is freely available for redistribution 